\title{
Dynamic Response of an Inhomogeneous Viscoelastic Pile in a Multilayered Soil to Transient Axial Loading
}

\author{
Zhiqing Zhang, ${ }^{1,2}$ Jian Zhou, ${ }^{1}$ Kuihua Wang, ${ }^{3}$ Qiang Li, ${ }^{4}$ and Kaifu Liu ${ }^{5}$ \\ ${ }^{1}$ Key Laboratory of Geotechnical and Underground Engineering of Ministry of Education, Tongji University, Shanghai 200092, China \\ ${ }^{2}$ College of Urban Construction, Zhejiang Shuren University, Hangzhou 310015, China \\ ${ }^{3}$ Key Laboratory of Soft Soils and Geoenvironmental Engineering, Ministry of Education, Zhejiang University, Hangzhou 310027, China \\ ${ }^{4}$ Department of Civil Engineering, Zhejiang Ocean University, Zhoushan 316004, China \\ ${ }^{5}$ School of Civil Engineering and Architecture, Zhejiang Sci-Tech University, Hangzhou 310018, China
}

Correspondence should be addressed to Jian Zhou; tjugezhoujian@tongji.edu.cn

Received 15 October 2014; Accepted 15 April 2015

Academic Editor: Igor Andrianov

Copyright ( 2015 Zhiqing Zhang et al. This is an open access article distributed under the Creative Commons Attribution License, which permits unrestricted use, distribution, and reproduction in any medium, provided the original work is properly cited.

A quasi-analytical solution is developed in this paper to investigate the mechanism of one-dimensional longitudinal wave propagating in inhomogeneous viscoelastic pile embedded in layered soil and subjected to a transient axial loading. At first, the pilesoil system is subdivided into several layers along the depth direction in consideration of the variation of cross-sectional acoustic impedance of the pile or differences in soil properties. Then, the dynamic governing equation of arbitrary soil layer is established in cylindrical coordinates and arbitrary viscoelastic pile segment is modeled using a single Voigt model. By using the Laplace transform and boundary conditions of the pile-soil system, the vertical impedance at the top of arbitrary pile segment is defined in a closed form in the frequency domain. Then by utilizing the method of recursion typically used in the Transfer Function technique, the vertical impedance at the pile top can be derived in the frequency domain and the velocity response of an inhomogeneous viscoelastic pile subjected to a semi-sine wave exciting force is obtained in a semi-analytical form in the time domain. Selected numerical results are obtained to study the mechanism of longitudinal wave propagating in a pile with a single defect or double defects.

\section{Introduction}

Pile vibration theory can provide valuable guidance for both the dynamic design of embedded foundations and dynamic nondestructive integrity testing of piles. For the dynamic design of pile foundations, the most concerned problem is the study of vibration characteristics of embedded piles in the low frequency range, and accordingly the dynamic reaction from the surrounding soil is an essential component in the relevant study. In light of this, many soil models, such as simplified continuum model [1-3], continuum model [46], and finite element model [7], have been developed to investigate the pile-soil dynamic interaction. For the dynamic nondestructive integrity testing of piles, low strain integrity testing technique has received wide application in assessing the construction quality of piles due to its relatively low-cost and simplicity. This testing technique is mainly based on the stress wave propagation theory through a bar. As a result, the theoretical study of a pile embedded in the soil and subjected to a dynamic vertical load under small deformation condition is increasingly becoming more important. For instance, Davis and Dunn [8] firstly proposed the mechanical admittance (or mobility function) method to determine the length and crosssectional area of a pile by applying a steady-state harmonic excitation at a specified set of frequencies on the pile top. In subsequent studies, Davis and Robertson [9] extended the mechanical admittance method to determine the pile head stiffness. Accounting for the convenience of transient excitation, Higgs [10] modified the mechanical admittance method by applying a vertical impact load on the pile top instead of steady-state harmonic excitation. After that, Lin et al. [11] introduced the impact-echo method to assess the integrity 
of piles by using the amplitude Fourier spectrum of the displacement record at the pile head instead of the mobility function. Watson et al. [12] developed a wavelet transform signal processing method instead of the conventional Fourier based methods to locate the position of the pile tip. It is noted that, in the low strain integrity pile testing where the hammer is relatively small compared to the pile dimension, Rayleigh and shear waves will radiate from the impact loading and the effects of three-dimensional (3D) waves on the near field responses are obvious. Subsequently, several researchers conducted relevant studies and proposed several methods to diminish the effects of $3 \mathrm{D}$ waves on the dynamic response of the pile top. Liao and Roesset $[13,14]$ investigated the influence of 3D waves on the dynamic response at the top of intact and defective pile by comparing one-dimensional (1D) wave theory and 3D axisymmetric finite element simulation results. It is shown from their studies that $3 \mathrm{D}$ effects are mainly influenced by the frequency and are more strongly manifested at high frequencies. Chow et al. [15] found that the velocity response curves resemble that of a pile with a defect near the pile head when considering 3D effects and further proposed that the potential source of error can be removed by maintaining a distance between hammer and receiver that is greater than $50 \%$ of the pile radius. Chai et al. [16] found that when the ratio of the characteristic length of an impact pulse to the pile radius is large enough, the components of Rayleigh waves in the wave field at the pile top are diminished. In this study, Chai et al. still proposed that the receiver should be placed at positions between $0.5 R$ and $0.75 R(R=$ pile radius $)$ from the pile axis to diminish the influence of the multireflections. Lu et al. [17] investigated the $3 \mathrm{D}$ characteristics of wave propagation in pipe-pile using elastodynamic finite integration technique and found that the interferences of Rayleigh waves are weakest at an angle of $90^{\circ}$ from where hammer hits. Furthermore, for the drilled piles with high slenderness ratio, it is difficult to detect the pile length and deep flaw from the traditional low strain pile integrity testing technique due to insufficient impact energy, testing signal decay, and soil-pile interaction. To solve this problem, $\mathrm{Ni}$ et al. [18] adjusted the testing devices for acquiring a lower frequency signal and developed a new numerical signal process method to enhance the reflection signals from the pile tip. It is also shown from the experimental results that the testing signal identification abilities can be improved by the modified method.

Most of the previous studies on the low strain pile integrity testing did not consider the effect of pile material damping, abrupt variation of surrounding soil properties, and multidefects in pile on the dynamic response. It is worth noting that the material damping indeed exists in a pile, the properties of the surrounding soil may change greatly in certain embedment depth, and a pile may contain several defects. Wang et al. [19] investigated the vertical dynamic response of an inhomogeneous viscoelastic pile and analyzed the effect of pile material damping and soil properties on the mechanical admittance and velocity response of the pile top. However, in this study, the surrounding soil reaction on the pile is approximately simulated by a general Voigt model which

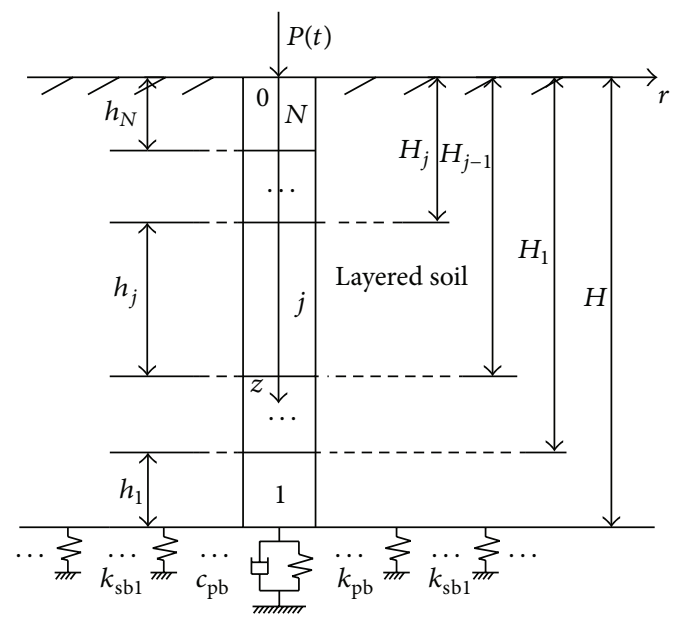

FIgURE 1: Model of pile-soil interaction.

cannot veritably and accurately reflect the pile-soil interaction. Therefore, the objective of this paper is to develop a practical solution to evaluate the theoretical capabilities of the nondestructive dynamic response method in detecting the existence and location of single or double defects in a viscoelastic pile embedded in a multilayered soil. Using the solution developed, a parametric study has been undertaken to investigate the mechanism of one-dimensional elastic longitudinal wave propagating in a defective pile. Finally, the theoretical model developed in the present paper is validated by comparison of the theoretical fitted curve and field measured curve of velocity response.

\section{Formulation of the Problem}

2.1. Geometry and Basic Assumption. The system examined is an inhomogeneous viscoelastic pile embedded in a multilayered soil and the geometric model is shown in Figure 1. To portray the variation of cross-sectional acoustic impedance (the product of density, cross-sectional area, and the one-dimensional elastic longitudinal wave velocity) of a pile or differences in soil properties, the pile-soil system is subdivided into a total of $N$ segments (layers) numbered by $1,2, \ldots, j, \ldots, N$ from pile tip to pile head. The thickness of the $j$ th $(1 \leq j \leq N)$ soil layer is equal to the length of the $j$ th $(1 \leq j \leq N)$ pile segment and is denoted by $h_{j}$. In order to derive an analytical or quasi-analytical solution for this problem, the assumptions are made as follows: (1) the surrounding soil is a linearly viscoelastic layer and the pile is vertical, elastic, and circular in cross-section. The pile and soil layer properties are assumed to be homogeneous within each segment or layer, respectively, but may change from segment to segment or layer to layer; (2) the pile-soil system is subjected to small deformations and strains during the vibration; the pile has a perfect contact with the surrounding soil during the vibration; (3) the free surface of the soil has no normal and shear stresses and the soil is infinite in the radial direction; (4) the soil at the base of the pile is modeled using a spring with elastic constant $k_{\mathrm{pb}}$ and a dashpot with 


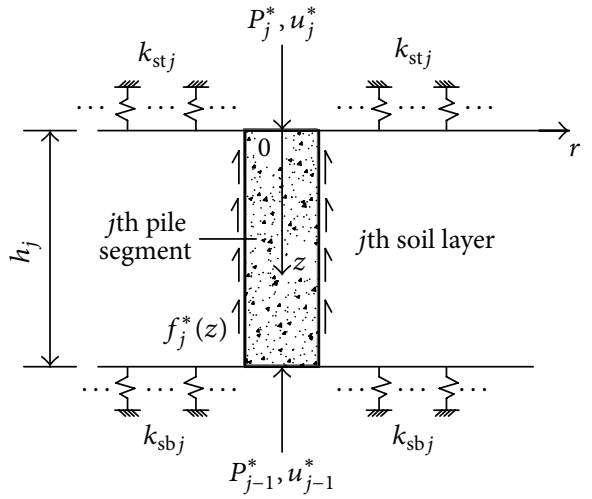

FIGURE 2: Pile segment used in derivation of impedance (in the local coordinate system).

damping coefficient $c_{\mathrm{pb}}$; (5) the contact traction acting at the $j$ th soil layer due to $j-1$ th and $j+1$ th soil layers is treated as the distributed Winkler subgrade model independent of the radial distance (see Figure 2).

2.2. Basic Equations and Solutions. The axisymmetric dynamic response of a linear viscoelastic soil is considered here and the governing equation of the $j$ th soil layer can be expressed in terms of vertical displacement as follows [20]:

$$
\begin{aligned}
{\left[\eta_{j}^{2}\right.} & \left.+i\left(D_{v j}\left(\eta_{j}^{2}-2\right)+2 D_{s j}\right)\right] \frac{\partial^{2} w_{j}(r, z, t)}{\partial z^{2}} \\
& +\left(1+i D_{s j}\right)\left(\frac{1}{r} \frac{\partial}{\partial r}+\frac{\partial^{2}}{\partial r^{2}}\right) w_{j}(r, z, t) \\
= & \frac{1}{V_{j}^{2}} \frac{\partial^{2} w_{j}(r, z, t)}{\partial t^{2}}
\end{aligned}
$$

where $\eta_{j}=\sqrt{\left(\lambda_{j}+2 G_{j}\right) / G_{j}}=\sqrt{2\left(1-\mu_{j}\right) /\left(1-2 \mu_{j}\right)} ; V_{j}=$ $\sqrt{G_{j} / \rho_{j}}$ is the shear wave velocity in the $j$ th soil layer; $\mu_{j}$ is Poisson ratio; $\lambda_{j}$ and $G_{j}$ are Lame's elastic constant and shear modulus of the $j$ th soil layer, respectively; $\lambda_{j}^{\prime}$ and $G_{j}^{\prime}$ are corresponding viscosity coefficients about Lame's elastic constant and shear modulus, respectively; $D_{s j}=G_{j}^{\prime} / G_{j}$ and $D_{v j}=\lambda_{j}^{\prime} / \lambda_{j}$ are hysteretic type damping which is irrespective with frequency; $w_{j}(r, z, t)$ is the vertical displacement of the $j$ th soil layer; $i=\sqrt{-1}$.

If the pile material is modeled as a single Voigt model, the axial displacement of the $j$ th pile segment is governed by the following one-dimensional equation of motion:

$$
\begin{aligned}
& \frac{E_{p j}}{\rho_{p j}} \frac{\partial^{2} u_{j}(z, t)}{\partial z^{2}}+\frac{\eta_{p j}}{\rho_{p j}} \frac{\partial^{3} u_{j}(z, t)}{\partial z^{2} \partial t}+\frac{2 \pi r_{j}}{\rho_{p j} A_{p j}} f_{j}(z, t) \\
& \quad=\frac{\partial^{2} u_{j}(z, t)}{\partial t^{2}},
\end{aligned}
$$

where $r_{j}, \rho_{p j}, E_{p j}, A_{p j}, \eta_{p j}$, and $u_{j}(z, t)$ are the radius, mass density, Young's modulus, cross-sectional area, viscoelastic damping coefficient, and axial displacement of the $j$ th pile segment, respectively; $f_{j}(z, t)$ denotes the contact traction along the $j$ th pile-soil interface due to the surrounding soil.

2.3. Initial Conditions of the Pile-Soil System. The pile-soil system is stationary in the initial state $(t=0)$. Accordingly, the corresponding initial conditions can be written as

$$
\begin{gathered}
\left.w_{j}(r, z, t)\right|_{t=0}=0 ; \\
\left.\frac{\partial w_{j}(r, z, t)}{\partial t}\right|_{t=0}=0 ; \\
(j=1,2, \ldots, N), \\
\left.u_{j}(z, t)\right|_{t=0}=0 \\
\left.\frac{\partial u_{j}(z, t)}{\partial t}\right|_{t=0}=0 ; \\
(j=1,2, \ldots, N) .
\end{gathered}
$$

2.4. Boundary and Continuity Conditions of the Pile-Soil System. Equations (1) and (2) cannot be solved analytically in the time domain; thus they are solved by using Laplace transform. In order to solve the pile-soil interaction problem, the boundary and continuity conditions of the pile-soil system will be formulated in the Laplace transform space and expressed in the local coordinate system (as shown in Figure 2). The Laplace transform of a function $f(r, z, t)$ with respect to $t$ is defined as

$$
f^{*}(r, z, s)=\int_{0}^{\infty} f(r, z, t) e^{-s t} d t
$$

where $s$ is the Laplace transform parameter.

2.4.1. The Boundary and Continuity Conditions of the Soil Layer. The boundary conditions of the $j$ th $(1 \leq j \leq N)$ soil layer can be written in the local coordinate system as

$$
\begin{array}{r}
w_{j}^{*}(r \longrightarrow \infty, z, s)=0 \\
{\left.\left[\frac{\partial w_{j}^{*}(r, z, s)}{\partial z}-\frac{k_{\mathrm{st} j}}{E_{s j}} w_{j}^{*}(r, z, s)\right]\right|_{z=0}=0} \\
{\left.\left[\frac{\partial w_{j}^{*}(r, z, s)}{\partial z}+\frac{k_{\mathrm{sb} j}}{E_{s j}} w_{j}^{*}(r, z, s)\right]\right|_{z=h_{j}}=0,}
\end{array}
$$

where $k_{\mathrm{st} j}$ and $k_{\mathrm{sb} j}$ denote the distributed reaction coefficient of the $j+1$ th and $j-1$ th soil layer acting on the $j$ th soil layer, respectively. For the $N$ th soil layer, $k_{\text {st } N}$ is equal to zero due to the free surface of the soil.

The continuity condition of the interface between the $j$ th and $j+1$ th $(1 \leq j \leq N-1)$ soil layer can be written as

$$
k_{\mathrm{st} j}=k_{\mathrm{sb}(j+1)} .
$$


2.4.2. The Boundary Conditions of the Pile Segment. The boundary condition at the top of the $j$ th $(1 \leq j \leq N)$ pile segment can be expressed in the local coordinate system as

$$
\left.\left[\frac{d u_{j}^{*}(z, s)}{d z}+\frac{\eta_{p j} s}{E_{p j}} \frac{d u_{j}^{*}(z, s)}{d z}\right]\right|_{z=0}=-\frac{P_{j}^{*}(s)}{E_{p j} A_{p j}},
$$

where $P_{j}^{*}(s)$ denotes the axial force of $j+1$ th pile segment acting on the top of the $j$ th pile segment. It is noted that $P_{N}^{*}(s)=P^{*}(s)$ for the $N$ th pile segment.

Allowing for the continuity conditions of the vertical displacement and axial force at the interface of adjacent pile segments, the boundary condition at the base of the $j$ th $(1 \leq$ $j \leq N$ ) pile segment can then be expressed in the local coordinate system as

$$
\begin{aligned}
& {\left.\left[\frac{d u_{j}^{*}(z, s)}{d z}+\frac{\eta_{p j} s}{E_{p j}} \frac{d u_{j}^{*}(z, s)}{d z}+\frac{u_{j}^{*}(z, s) Z_{j-1}}{E_{p j} A_{p j}}\right]\right|_{z=h_{j}}} \\
& \quad=0
\end{aligned}
$$

where $Z_{j-1}$ denotes the vertical impedance at the top of the $j-1$ th pile segment. It is worth noting that $Z_{0}=k_{\mathrm{pb}}+s c_{\mathrm{pb}}$ for the 1st pile segment. Moreover, soil response at the pile toe is approximated by the response of a vertically vibrating rigid disk on the surface of an elastic half-space. The soil spring and damping coefficient at the pile toe can be given as follows [21]:

$$
\begin{aligned}
k_{\mathrm{pb}} & =\frac{4 G_{0} r_{1}}{1-\mu_{0}}, \\
c_{\mathrm{pb}} & =\frac{3.4 r_{1}^{2} \sqrt{\rho_{0} G_{0}}}{1-\mu_{0}},
\end{aligned}
$$

where $G_{0}$ and $\mu_{0}$ denote the shear modulus and Poisson's ratio of the soil underlying the pile toe.

2.4.3. The Continuity Conditions of the Displacement and Stress of the $j$ th $(1 \leq j \leq N)$ Pile-Soil Interface. Consider the following:

$$
\begin{aligned}
\left.w_{j}^{*}(r, z, s)\right|_{r=r_{j}} & =u_{j}^{*}(z, s), \\
f_{j}^{*}(z, s) & =\tau_{r z j}^{*}(r, z, s) \\
& =\left.G_{j}\left(1+i D_{s j}\right) \frac{\partial w_{j}^{*}(r, z, s)}{\partial r}\right|_{r=r_{j}} .
\end{aligned}
$$

2.5. Solution of the jth Soil Layer. Combining (1) with the initial conditions given in (3) and applying the Laplace transform yield

$$
\begin{aligned}
\left\{\eta_{j}^{2}\right. & \left.+i\left[D_{v j}\left(\eta_{j}^{2}-2\right)+2 D_{s j}\right]\right\} \frac{\partial^{2} w_{j}^{*}(r, z, s)}{\partial z^{2}} \\
& +\left(1+i D_{s j}\right)\left(\frac{1}{r} \frac{\partial}{\partial r}+\frac{\partial^{2}}{\partial r^{2}}\right) w_{j}^{*}(r, z, s) \\
= & \left(\frac{s}{V_{j}}\right)^{2} w_{j}^{*}(r, z, s) .
\end{aligned}
$$

To solve (15), a single-variable function $w_{j}^{*}(r, z, s)=$ $R_{j}(r) Z_{j}(z)$ is introduced and substituting $w_{j}^{*}(r, z, s)$ into (15) yields

$$
\begin{array}{r}
\frac{d^{2} Z_{j}(z)}{d z^{2}}+J_{j}^{2} Z_{j}(z)=0, \\
\frac{d^{2} R_{j}(r)}{d r^{2}}+\frac{1}{r} \frac{d R_{j}(r)}{d r}-q_{j}^{2} R_{j}(r)=0,
\end{array}
$$

where $q_{j}^{2}=\left(\left\{\eta_{j}^{2}+i\left[D_{v j}\left(\eta_{j}^{2}-2\right)+2 D_{s j}\right]\right\} J_{j}^{2}+\left(s / V_{j}\right)^{2}\right) /\left(1+i D_{s j}\right)$.

The general solutions of (16) can be written as

$$
\begin{aligned}
& Z_{j}(z)=C_{j} \sin \left(J_{j} z\right)+D_{j} \cos \left(J_{j} z\right), \\
& R_{j}(r)=A_{j} K_{0}\left(q_{j} r\right)+B_{j} I_{0}\left(q_{j} r\right),
\end{aligned}
$$

where $I_{0}\left(q_{j} r\right)$ and $K_{0}\left(q_{j} r\right)$ are the modified Bessel functions of the first and second kinds of zero order, respectively; $A_{j}, B_{j}, C_{j}$, and $D_{j}$ are the constants which remain to be determined later from the boundary conditions.

Since the function $I_{0}\left(q_{j} r\right) \rightarrow \infty$ when $r \rightarrow \infty$, the constant $B_{j}$ in (18) should vanish to zero to satisfy the boundary condition given in (6). Then, the substitution of boundary conditions given in (7) and (8) into (17) results in

$$
\tan \left(h_{j} J_{j}\right)=\frac{\left(\bar{k}_{\mathrm{sb} j}+\bar{k}_{\mathrm{st} j}\right) h_{j} J_{j}}{\left(h_{j} J_{j}\right)^{2}-\bar{k}_{\mathrm{sb} j} \bar{k}_{\mathrm{st} j}}
$$

where $\bar{k}_{\mathrm{sb} j}=k_{\mathrm{sb} j} h_{j} / E_{s j}$ and $\bar{k}_{\mathrm{st} j}=k_{\mathrm{st} j} h_{j} / E_{s j}$ denote the dimensionless reaction coefficients at the base and top of the $j$ th soil layer, respectively.

Then, the solution of (15) can be written in a series expansion as

$$
w_{j}^{*}(r, z, s)=\sum_{m=1}^{\infty} A_{m j} K_{0}\left(q_{m j} r\right) \sin \left(J_{m j} z+\varphi_{m j}\right),
$$

where $\varphi_{m j}=\arctan \left(J_{m j} h_{j} / \bar{k}_{\mathrm{st} j}\right), q_{m j}^{2}=\left(\left[\eta_{j}^{2}+i\left(D_{v j}\left(\eta_{j}^{2}-2\right)+\right.\right.\right.$ $\left.\left.\left.2 D_{s j}\right)\right] J_{m j}^{2}+\left(s / V_{j}\right)^{2}\right) /\left(1+i D_{s j}\right)$.

Based on continuity condition given in (14), the contact traction along the 1st pile-soil interface can be expressed as

$$
\begin{aligned}
\left.f_{j}^{*}(r, z, s)\right|_{r=r_{j}}=\left.G_{j}\left(1+i D_{s j}\right) \frac{\partial w_{j}^{*}(r, z, s)}{\partial r}\right|_{r=r_{j}} \\
=-G_{j}\left(1+i D_{s j}\right) \\
\quad \cdot \sum_{m=1}^{\infty} A_{m j} q_{m j} K_{1}\left(q_{m j} r_{j}\right) \sin \left(J_{m j} z+\varphi_{m j}\right)
\end{aligned}
$$

where $K_{1}\left(q_{m j} r\right)$ denotes the modified Bessel functions of the second kind of the first order. 
2.6. Solution of the jth Pile Segment. Based on the initial conditions given in (4), applying the Laplace transform into (2) yields

$$
\begin{aligned}
& \left(\frac{E_{p j}}{\rho_{p j}}+\frac{\eta_{p j} s}{\rho_{p j}}\right) \frac{d^{2} u_{j}^{*}(z, s)}{d z^{2}}+\frac{2 \pi r_{j}}{\rho_{p j} A_{p j}} f_{j}^{*}(z, s) \\
& =s^{2} u_{j}^{*}(z, s) .
\end{aligned}
$$

For the $j$ th pile segment, by utilizing the stress continuity condition that is given in (14), substituting (21) into (22) gives

$$
\begin{aligned}
& \left(\frac{E_{p j}}{\rho_{p j}}+\frac{\eta_{p j} s}{\rho_{p j}}\right) \frac{d^{2} u_{j}^{*}(z, s)}{d z^{2}}-s^{2} u_{j}^{*}(z, s) \\
& =\frac{2 \pi r_{j} G_{j}\left(1+i D_{s j}\right)}{\rho_{p j} A_{p j}} \\
& \cdot \sum_{m=1}^{\infty} A_{m j} q_{m j} K_{1}\left(q_{m j} r_{j}\right) \sin \left(J_{m j} z+\varphi_{m j}\right) .
\end{aligned}
$$

The solution of (23) can be written as

$$
\begin{aligned}
u_{j}^{*}(z, s)= & \alpha_{1 j} e^{\gamma_{j} z}+\alpha_{2 j} e^{-\gamma_{j} z} \\
& +\sum_{m=1}^{\infty} \psi_{m j} \sin \left(J_{m j} z+\varphi_{m j}\right),
\end{aligned}
$$

where $\psi_{m j}=-2 G_{j}\left(1+i D_{s j}\right) A_{m j} q_{m j} K_{1}\left(q_{m j} r_{j}\right) /\left(r_{j}\left[E_{p j}(1+\right.\right.$ $\left.\left.\left.\bar{\eta}_{p j} s t_{c}\right) J_{m j}^{2}+\rho_{p j} s^{2}\right]\right) ; \gamma_{j}=\sqrt{\rho_{p j} s^{2} /\left[E_{p j}\left(1+\bar{\eta}_{p j} s t_{c}\right)\right]} ; \alpha_{1 j}$ and $\alpha_{2 j}$ are undetermined constants; $\bar{\eta}_{p j}=\eta_{p j} /\left(E_{p j} t_{c}\right)$ is the dimensionless damping coefficient of $j$ th pile segment; $t_{c}=$ $\sum_{j=1}^{N}\left(h_{j} / V_{p j}\right)$ is the time of the elastic longitudinal wave propagating from the pile top to pile tip; $V_{p j}=\sqrt{E_{p j} / \rho_{p j}}$ is the $1 \mathrm{D}$ elastic longitudinal wave velocity in the $j$ th pile segment.

By using the displacement continuity condition that is given in (13), substituting (20) and (24) into (13) results in

$$
\begin{gathered}
\alpha_{1 j} e^{\gamma_{j} z}+\alpha_{2 j} e^{-\gamma_{j} z}+\sum_{m=1}^{\infty} \psi_{m j} \sin \left(J_{m j} z+\varphi_{m j}\right) \\
=\sum_{m=1}^{\infty} A_{m j} K_{0}\left(q_{m j} r_{j}\right) \sin \left(J_{m j} z+\varphi_{m j}\right) .
\end{gathered}
$$

By invoking the orthogonality of eigenfunctions $\sin \left(J_{m j} z+\varphi_{m j}\right)(m=1,2,3, \ldots)$, multiplying $\sin \left(J_{m j} z+\varphi_{m j}\right)$ on both sides of (25), and then integrating over the interval $z=\left[0, h_{j}\right]$, the undetermined coefficient $A_{m j}$ is found to be

$$
A_{m j}=\frac{1}{L_{m j} E_{m j}} \int_{0}^{h_{j}} Q_{j} \sin \left(J_{m j} z+\varphi_{m j}\right) d z,
$$

where $L_{m j}=h_{j} / 2-\left(\sin \left(2 J_{m j} h_{j}+2 \varphi_{m j}\right)-\sin \left(2 \varphi_{m j}\right)\right) /\left(4 J_{m j}\right)$, $Q_{j}=\alpha_{1 j} e^{\gamma_{j} z}+\alpha_{2 j} e^{-\gamma_{j} z}$,

$$
E_{m j}=\frac{2 G_{j}\left(1+i D_{s j}\right) q_{m j} K_{1}\left(q_{m j} r_{j}\right)}{r_{j}\left[E_{p j}\left(1+\bar{\eta}_{p j} s t_{c}\right) J_{m j}^{2}+\rho_{p j} s^{2}\right]}+K_{0}\left(q_{m j} r_{j}\right) \text {. }
$$

It is mathematically convenient at this stage to introduce the following dimensionless variables:

$$
\begin{gathered}
\bar{L}_{m j}=\frac{L_{m j}}{h_{j}} ; \\
\bar{q}_{m j}=q_{m j} h_{j} ; \\
\bar{r}_{j}=\frac{r_{j}}{h_{j}} ; \\
\bar{J}_{m j}=J_{m j} h_{j} ; \\
\bar{\gamma}_{j}=\gamma_{j} h_{j} .
\end{gathered}
$$

The amplitude of the vertical displacement of the $j$ th pile segment is then given by

$$
\begin{aligned}
u_{j}^{*}(z, s)= & \alpha_{1 j}\left[e^{\gamma_{j} z}+\sum_{m=1}^{\infty} \xi_{m j} \sin \left(J_{m j} z+\varphi_{m j}\right)\right] \\
& +\alpha_{2 j}\left[e^{-\gamma_{j} z}+\sum_{m=1}^{\infty} \zeta_{m j} \sin \left(J_{m j} z+\varphi_{m j}\right)\right],
\end{aligned}
$$

where

$$
\begin{aligned}
& \xi_{m j}=v_{m j} \frac{\bar{\gamma}_{j}\left[e^{\bar{\gamma}_{j}} \sin \left(\bar{J}_{m j}+\varphi_{m j}\right)-\sin \left(\varphi_{m j}\right)\right]-\bar{J}_{m j}\left[e^{\bar{\gamma}_{j}} \cos \left(\bar{J}_{m j}+\varphi_{m j}\right)-\cos \left(\varphi_{m j}\right)\right]}{\bar{J}_{m j}^{2}+\bar{\gamma}_{j}^{2}}, \\
& \zeta_{m j}=v_{m j} \frac{-\bar{\gamma}_{j}\left[e^{-\bar{\gamma}_{j}} \sin \left(\bar{J}_{m j}+\varphi_{m j}\right)-\sin \left(\varphi_{m j}\right)\right]-\bar{J}_{m j}\left[e^{-\bar{\gamma}_{j}} \cos \left(\bar{J}_{m j}+\varphi_{m j}\right)-\cos \left(\varphi_{m j}\right)\right]}{\bar{J}_{m j}^{2}+\bar{\gamma}_{j}^{2}}, \\
& v_{m j}=\frac{-2 G_{j}\left(1+i D_{s j}\right) \bar{q}_{m j} K_{1}\left(\bar{q}_{m j} \bar{r}_{j}\right)}{\left[E_{p j}\left(1+\bar{\eta}_{p j} s t_{c}\right) \bar{J}_{m j}^{2}+\rho_{p j} h_{j}^{2} s^{2}\right] \bar{r}_{j} \bar{L}_{m j} E_{m j}} .
\end{aligned}
$$


Based on the boundary conditions of the $j$ th pile segment, then substituting (10) and (11) into (29), the variables $\alpha_{1 j}, \alpha_{2 j}$ are obtained and the vertical impedance function at the top end of the $j$ th pile segment can be written as

$$
\begin{aligned}
Z_{j}(s) & =\frac{P_{j}(s)}{u_{j}(z=0, s)} \\
& =-E_{p j}\left(A_{p j}+\bar{\eta}_{p j} s t_{c} A_{p j}\right) \frac{\left(\alpha_{1 j} / \alpha_{2 j}\right)\left[\gamma_{j}+\sum_{m=1}^{\infty} \xi_{m j} J_{m j} \cos \left(\varphi_{m j}\right)\right]+\left[-\gamma_{j}+\sum_{m=1}^{\infty} \zeta_{m j} J_{m j} \cos \left(\varphi_{m j}\right)\right]}{\left(\alpha_{1 j} / \alpha_{2 j}\right)\left[1+\sum_{m=1}^{\infty} \xi_{m j} \sin \left(\varphi_{m j}\right)\right]+\left[1+\sum_{m=1}^{\infty} \zeta_{m j} \sin \left(\varphi_{m j}\right)\right]}
\end{aligned}
$$

where

$$
\begin{aligned}
\frac{\alpha_{1 j}}{\alpha_{2 j}} & =-\frac{\left(1+\bar{\eta}_{p j} s t_{c}\right)\left[-\bar{\gamma}_{j} e^{-\bar{\gamma}_{j}}+\sum_{m=1}^{\infty} \zeta_{m j} J_{m j} \cos \left(\bar{J}_{m j}+\varphi_{m j}\right)\right]+\bar{Z}_{j-1}\left[e^{-\bar{\gamma}_{j}}+\sum_{m=1}^{\infty} \zeta_{m j} \sin \left(\bar{J}_{m j}+\varphi_{m j}\right)\right]}{\left(1+\bar{\eta}_{p j} s t_{c}\right)\left[\bar{\gamma}_{j} e^{\bar{\gamma}_{j}}+\sum_{m=1}^{\infty} \xi_{m j} J_{m j} \cos \left(\bar{J}_{m j}+\varphi_{m j}\right)\right]+\bar{Z}_{j-1}\left[e^{\bar{\gamma}_{j}}+\sum_{m=1}^{\infty} \xi_{m j} \sin \left(\bar{J}_{m j}+\varphi_{m j}\right)\right]} \\
\bar{Z}_{j-1} & =\frac{Z_{j-1} h_{j}}{E_{p j} A_{p j}}
\end{aligned}
$$

For the 1st pile segment, $\bar{Z}_{0}=\left(k_{\mathrm{pb}}+s c_{\mathrm{pb}}\right) h_{1} /\left(E_{p 1} A_{p 1}\right)$ denotes the dimensionless reaction coefficient at the pile base.
Through recursion impedance function from the 1st pile segment to the $N$ th pile segment, the vertical impedance function at the pile head can be expressed as

$$
\begin{aligned}
Z_{N}(s) & =\frac{P_{N}(s)}{u_{N}(z=0, s)} \\
& =-E_{p N}\left(A_{p N}+\bar{\eta}_{p N} s t_{c} A_{p N}\right) \frac{\left(\alpha_{1 N} / \alpha_{2 N}\right)\left[\gamma_{N}+\sum_{m=1}^{\infty} \xi_{m N} J_{m N} \cos \left(\varphi_{m N}\right)\right]+\left[-\gamma_{N}+\sum_{m=1}^{\infty} \zeta_{m N} J_{m N} \cos \left(\varphi_{m N}\right)\right]}{\left(\alpha_{1 N} / \alpha_{2 N}\right)\left[1+\sum_{m=1}^{\infty} \xi_{m N} \sin \left(\varphi_{m N}\right)\right]+\left[1+\sum_{m=1}^{\infty} \zeta_{m N} \sin \left(\varphi_{m N}\right)\right]}
\end{aligned}
$$

Letting $s=i \omega$, the frequency response function of displacement (admittance function of displacement) at the pile head can be written as

$$
\begin{aligned}
H_{u}(\omega) & =\frac{1}{Z_{N}} \\
& =-\frac{1}{E_{p N}\left(A_{p N}+\bar{\eta}_{p N} s t_{c} A_{p N}\right)} \frac{\left(\alpha_{1 N} / \alpha_{2 N}\right)\left[1+\sum_{m=1}^{\infty} \xi_{m N} \sin \left(\varphi_{m N}\right)\right]+\left[1+\sum_{m=1}^{\infty} \zeta_{m N} \sin \left(\varphi_{m N}\right)\right]}{\left(\alpha_{1 N} / \alpha_{2 N}\right)\left[\gamma_{N}+\sum_{m=1}^{\infty} \xi_{m N} J_{m N} \cos \left(\varphi_{m N}\right)\right]+\left[-\gamma_{N}+\sum_{m=1}^{\infty} \zeta_{m N} J_{m N} \cos \left(\varphi_{m N}\right)\right]}
\end{aligned}
$$

Then, the response function of velocity (or admittance function of velocity) at the pile head can be written as

$$
H_{v}(\omega)=i \omega H_{u}(\omega)=\frac{1}{\rho_{p N} A_{p N} V_{p N}} H_{v}^{\prime}(\omega)
$$

where $H_{v}^{\prime}(\omega)$ is the dimensionless response function of velocity at the pile head and

$$
H_{v}^{\prime}(\omega)=-\frac{i \omega \rho_{p N} A_{p N} V_{p N}}{E_{p N}\left(A_{p N}+\bar{\eta}_{p N} s t_{c} A_{p N}\right)} \frac{\left(\alpha_{1 N} / \alpha_{2 N}\right)\left[1+\sum_{m=1}^{\infty} \xi_{m N} \sin \left(\varphi_{m N}\right)\right]+\left[1+\sum_{m=1}^{\infty} \zeta_{m N} \sin \left(\varphi_{m N}\right)\right]}{\left(\alpha_{1 N} / \alpha_{2 N}\right)\left[\gamma_{N}+\sum_{m=1}^{\infty} \xi_{m N} J_{m N} \cos \left(\varphi_{m N}\right)\right]+\left[-\gamma_{N}+\sum_{m=1}^{\infty} \zeta_{m N} J_{m N} \cos \left(\varphi_{m N}\right)\right]}
$$




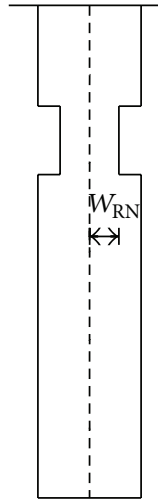

(a)

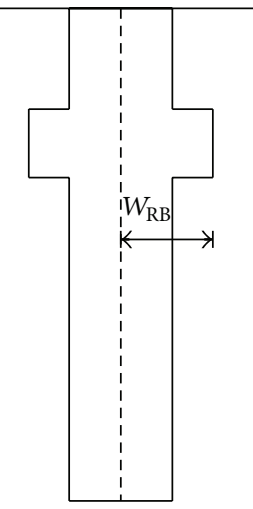

(b)

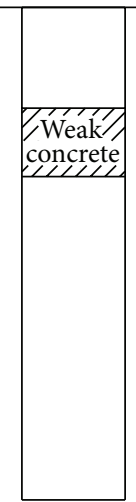

(c)

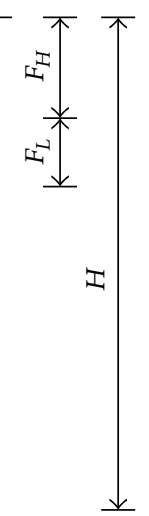

FIGURE 3: Geometry of typical defective piles: (a) pile with a neck, (b) pile with a bulb, and (c) pile with a weak concrete.

If the Fourier transform of the longitudinal exciting force $P(t)$ acting on the pile top is denoted by $P(\omega)$, the velocity response of the pile top in the time domain can be calculated by convolution theorem as

$$
V(t)=\operatorname{IFT}[P(\omega) H(\omega)] .
$$

When the force at the top of the pile is a half-sine pulse,

$$
P(t)= \begin{cases}Q_{\max } \sin \left(\frac{\pi t}{T_{0}}\right) & t<T_{0} \\ 0 & t \geq T_{0},\end{cases}
$$

where $T_{0}$ and $Q_{\max }$ denote the duration of the impulse or impulse width and the maximum amplitude of the exciting force, respectively. Then, the velocity response of the pile top in the time domain can be further expressed as

$$
\begin{aligned}
V(t)= & \frac{1}{2 \pi} \int_{-\infty}^{+\infty} \frac{Q_{\max }}{V_{p N} A_{p N} \rho_{p N}} H_{v}(\omega) \\
& \cdot \frac{\pi T_{0}}{\pi^{2}-T_{0}^{2} \omega^{2}}\left(1+e^{-i \omega T_{0}}\right) e^{i \omega T_{0}} d \omega .
\end{aligned}
$$

To facilitate analysis, it is useful to introduce the normalized velocity response:

$$
V^{\prime}(t)=\frac{V(t)}{\max [V(t)]},
$$

where $\max [V(t)]$ denotes the maximum value of $V(t)$.

\section{Problem Definition}

The possible defects due to voids or inclusions in a pile after construction can generally be categorized as neck, bulb, and weak concrete. The geometry of typical defective piles is plotted in Figure 3. $W_{\mathrm{RN}}$ (neck width) and $W_{\mathrm{RB}}$ (bulb width) denote the radius of the neck and bulb, respectively. $F_{H}$ and $F_{L}$ denote the embedment depth and length of the defect, respectively. If a pile contains more than one defect (i.e., two defects), the geometry of defective pile can be the combination of Figures 3(a), 3(b), and 3(c).

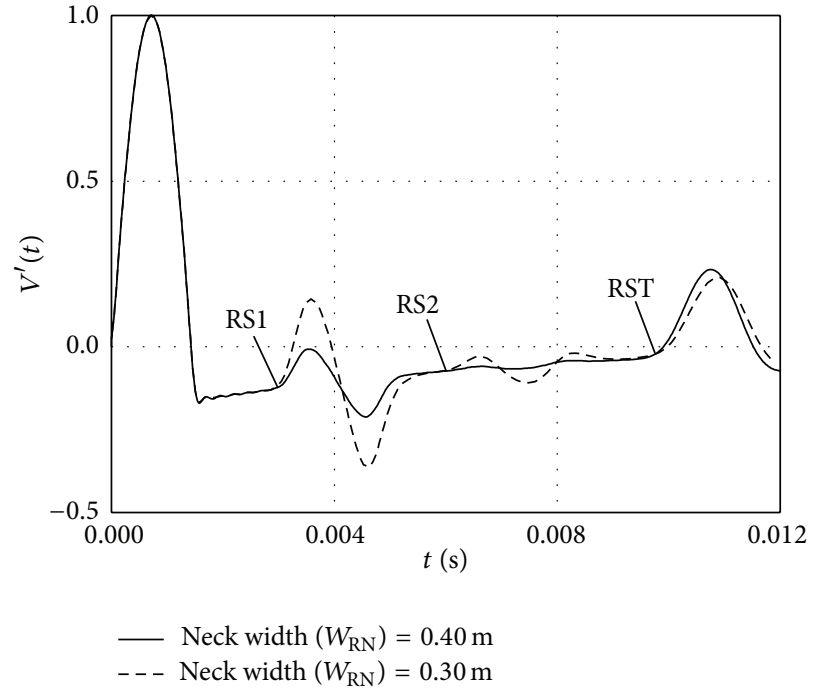

FIGURE 4: Variation of the normalized velocity response of the pile top with the neck width $\left(N=3, h_{1}=12.5 \mathrm{~m}, F_{L}=h_{2}=0.5 \mathrm{~m}\right.$, $\left.F_{H}=h_{1}=6.0 \mathrm{~m}\right)$.

\section{Results and Discussion}

In the past, the mechanical admittance method has received wide application in the field pile integrity test. However, the mechanical admittance method is difficult to accurately identify defects when a pile contains more than one flaw. Furthermore, quick attenuation of the amplitude of admittance curve in the high frequency range caused by the pile material damping can also make the location of the defect hard to be accurately detected. As a result, in previous few years, the method by virtue of time history of velocity response of the pile top has then been widely used instead of the mechanical admittance method in China due to its simplicity of subsequent parameter analysis. Accordingly, the influence of geometric and physical characteristics of the defects and pile material damping on the velocity response of the pile top will be investigated in the following section. Unless otherwise specified, the pile properties employed in the following analysis are $j=$ $1,2, \ldots, N, \rho_{p j}=2500 \mathrm{~kg} / \mathrm{m}^{3}, V_{p j}=3790 \mathrm{~m} / \mathrm{s}, \bar{\eta}_{p j}=0.0015$, $H=19 \mathrm{~m}, r_{j}=0.5 \mathrm{~m}, t_{0}=1.5 \times 10^{-3} \mathrm{~s}$ and Poisson's ratio $=0.2$; the soil properties are $\rho_{j}=1800 \mathrm{~kg} / \mathrm{m}^{3}, V_{s j}=120 \mathrm{~m} / \mathrm{s}$, $D_{s j}=D_{v j}=0.02, \bar{k}_{\mathrm{sb} j}=\bar{k}_{\mathrm{st} j}=0.01$ and Poisson's ratio $=0.3$.

\subsection{Pile Containing a Single Defect}

4.1.1. Effect of Width of Defect. Figure 4 shows the influence of the neck width $\left(W_{\mathrm{RN}}\right)$ on the velocity response of the pile top. It can be seen from Figure 4 that the first reflective signal from the defect (RS1) arrives at $t=t_{\mathrm{RS} 1}=0.00300 \mathrm{~s}\left(t_{\mathrm{RS} 1}\right.$ is the time of arrival of the first reflective signal from the defect). Accordingly, the embedment depth of the defect can be calculated as $F_{H}=V_{\text {rod }} \times t_{\mathrm{RS} 1} / 2=5.68 \mathrm{~m}\left(V_{\text {rod }}\right.$ is the $1 \mathrm{D}$ elastic longitudinal wave velocity in an intact pile, error $=$ $5.3 \%$ ). The reflective signal from the pile tip (RST) arrives at $t=t_{\mathrm{RST}}=0.00967 \mathrm{~s}\left(t_{\mathrm{RST}}\right.$ is the time of arrival of the reflective 


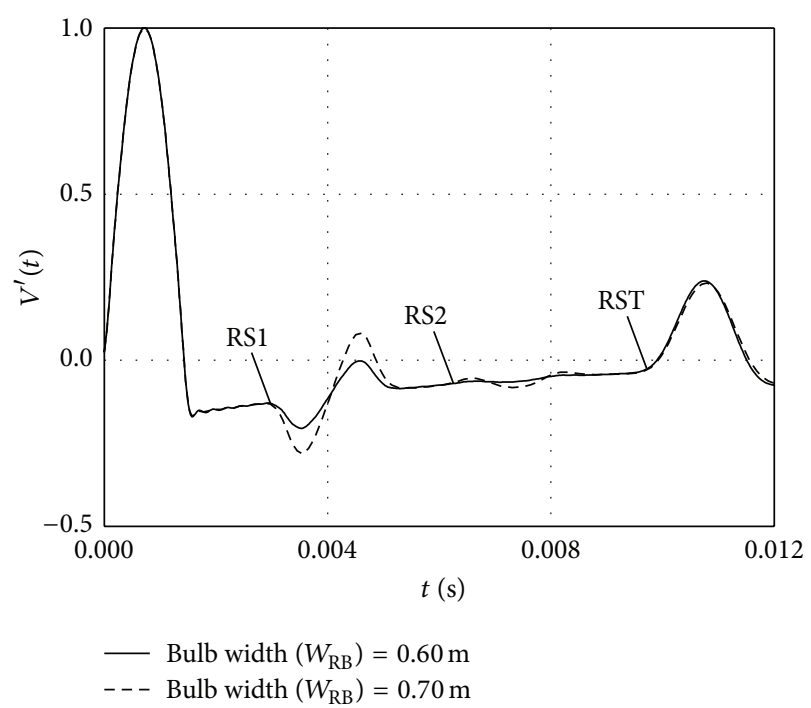

FIGURE 5: Variation of the normalized velocity response of the pile top with the bulb width $\left(N=3, h_{1}=12.5 \mathrm{~m}, F_{L}=h_{2}=0.5 \mathrm{~m}\right.$, $\left.F_{H}=h_{1}=6.0 \mathrm{~m}\right)$.

signal from the pile tip), and the length of the pile $H=V_{\text {rod }} \times$ $t_{\mathrm{RST}} / 2=18.32 \mathrm{~m}$ (error $\left.=3.6 \%\right)$. When the degree of defect is relatively great $\left(W_{\mathrm{RN}}=0.3 \mathrm{~m}\right)$ (namely, the peak of RS1 is above zero axis), the second reflective signal from the defect (RS2) appears and arrives at $t \approx 2 t_{\mathrm{RS} 1}(t=0.00598 \mathrm{~s})$, and the amplitude of RS2 is much lower than that of RS1 because of quick dissipation of the energy. It is worth noting that this signal (RS2) can be used to further check the location of the defect. For instance, the embedment of the defect can be calculated as $F_{H}=V_{\text {rod }} \times t_{\mathrm{RS} 2} / 4=5.67 \mathrm{~m}$ (error $=5.5 \%$ ). It is also observed from Figure 4 that the amplitude of RS1 increases greatly with the decrease of $W_{\mathrm{RN}}$. This result indicates that the higher the amplitude of the reflective signal is, the greater the degree of defect will be. Furthermore, for the pile with a neck, the phase of RS1 is the same as that of the incident pulse due to the abrupt decrease of the cross-sectional area.

Figure 5 shows the influence of the bulb width $\left(W_{\mathrm{RB}}\right)$ on the velocity response of the pile top. It can be seen from Figure 5 that RS1 and RST arrive at $t=t_{\mathrm{RS} 1}=0.00296 \mathrm{~s}$ and $t=t_{\mathrm{RST}}=0.00973 \mathrm{~s}$, respectively. Therefore, $F_{H}=$ $V_{\text {rod }} \times t_{\mathrm{RS} 1} / 2=5.61 \mathrm{~m}($ error $=6.5 \%)$ and $H=V_{\text {rod }} \times t_{\mathrm{RST}} / 2=$ $18.32 \mathrm{~m}$ (error $=3.6 \%$ ). It is also observed from Figure 6 that the amplitude of the RS1 increases greatly with the increase of $W_{\mathrm{RB}}$. Moreover, the phase of RS1 is the opposite to that of the incident pulse due to the abrupt increase of the crosssectional area. However, the phase of RS2 is the same as that of the incident pulse, which is similar to the reflective signal of the pile with a neck. As a result, RS2 is easily identified as a defect by mistake.

Figure 6 shows the influence of the longitudinal wave velocity in a weak concrete $\left(V_{p 2}\right)$ on the velocity response of the pile top. It can be seen from Figure 6 that the velocity response curve of the pile with a weak concrete is similar to that of the pile with a neck. The phase of RS1 is the same as that of the incident pulse due to the abrupt decrease of $V_{p 2}$ and

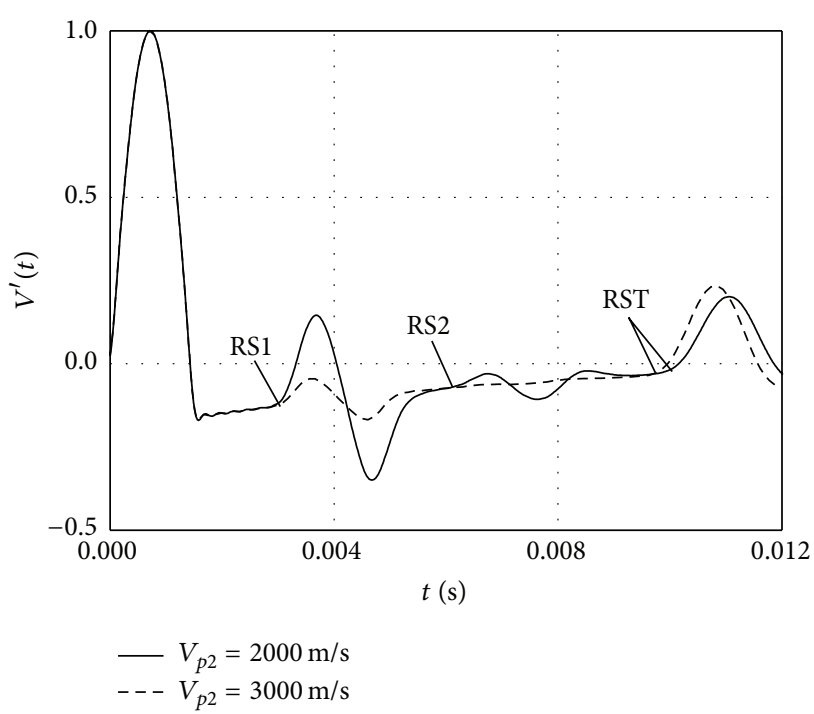

FIGURE 6: Variation of the normalized velocity response of the pile top with the longitudinal wave velocity in weak concrete $(N=3$, $h_{1}=12.5 \mathrm{~m}, F_{L}=h_{2}=0.5 \mathrm{~m}, F_{H}=h_{1}=6.0 \mathrm{~m}$ ).

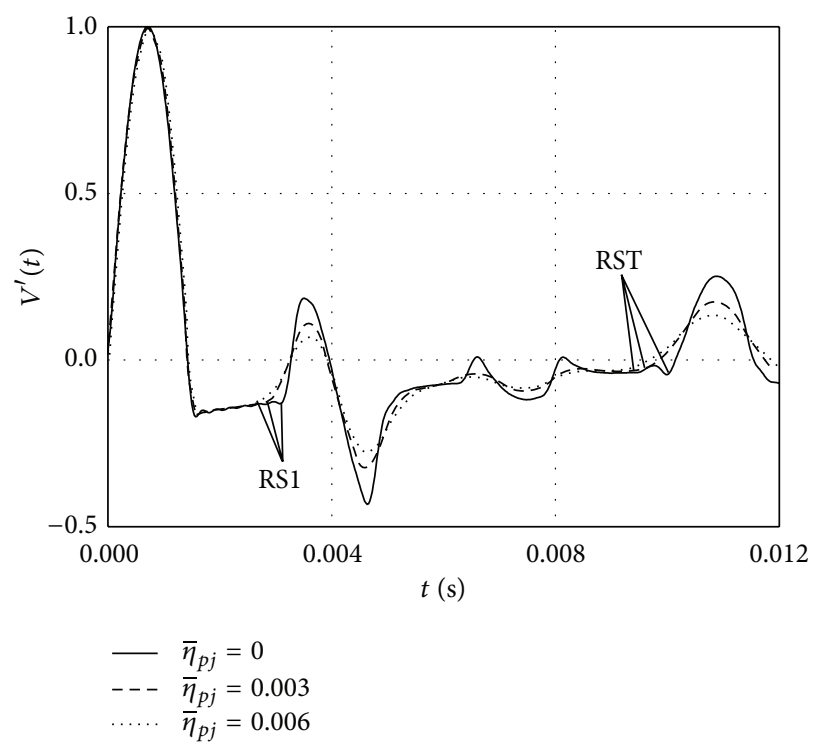

FIGURE 7: Variation of the normalized velocity response of the pile top with material damping of the pile $\left(N=3, W_{\mathrm{RN}}=0.30 \mathrm{~m}, h_{1}=\right.$ $\left.12.5 \mathrm{~m}, F_{L}=h_{2}=0.5 \mathrm{~m}, F_{H}=h_{1}=6.0 \mathrm{~m}\right)$.

the amplitude of RS1 increases greatly with the decrease of $V_{p 2}$. Furthermore, the time of arrival of RST increases obviously with the decrease of $V_{p 2}$. The reason for this result is that RST will need much more time to arrive at the pile top as $V_{p 2}$ decreases.

4.1.2. Effect of Material Damping of the Pile. Figure 7 shows the influence of material damping of the pile on the velocity response of the pile top. It can be seen from Figure 7 that the material damping of the pile has marked influence on the velocity response of the pile top. The amplitude of RS1 and RST decreases markedly with the increasing material 


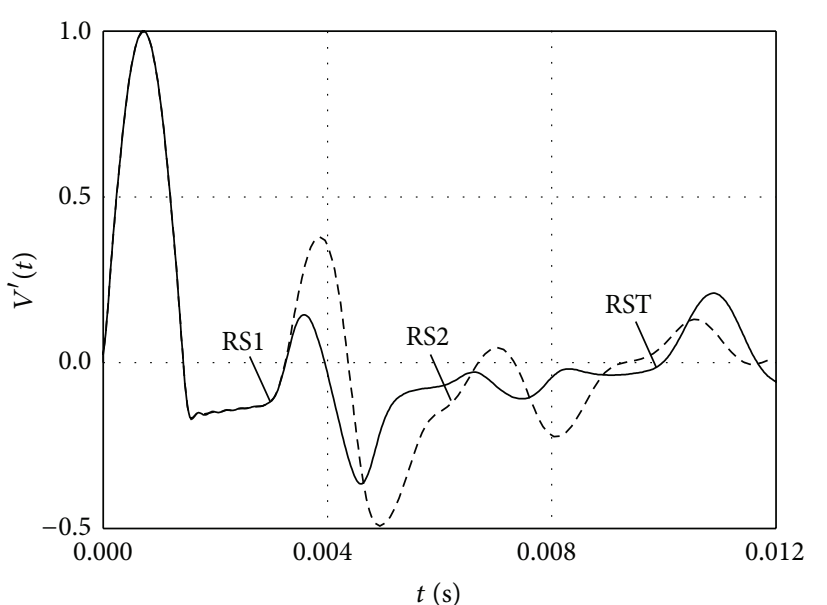

— Neck length $\left(F_{L}\right)=0.5 \mathrm{~m}$

-- Neck length $\left(F_{L}\right)=2.0 \mathrm{~m}$

FIGURE 8: Variation of the normalized velocity response of the pile top with neck length $\left(N=3, W_{\mathrm{RN}}=0.30 \mathrm{~m}, F_{H}=h_{1}=6.0 \mathrm{~m}\right)$.

damping of the pile, which results in the fact that the degree of defect seems to be smaller than the actual degree. Moreover, the width of RS1 and RST shows obvious increase with the increase of pile material damping, resulting in the marginal of the reflective signal becoming more and more ambiguous. As a result, it is difficult to accurately obtain the time of arrival of the signal reflected from the defect and determine the location of the defect. For instance, RS1 arrives at $t=$ $t_{\mathrm{RS} 1}=0.00311 \mathrm{~s}$ and $F_{H}=V_{\text {rod }} \times t_{\mathrm{RS} 1} / 2=5.89 \mathrm{~m}$ (error $=$ $1.8 \%)$, when pile material damping is not considered $\left(\bar{\eta}_{j}=\right.$ 0 ). However, when pile material damping is considered (i.e., $\left.\bar{\eta}_{j}=0.006\right)$, RS1 arrives at $t=t_{\mathrm{RS} 1}=0.00265 \mathrm{~s}$, and $F_{H}=$ $V_{\text {rod }} \times t_{\mathrm{RS} 1} / 2=5.02 \mathrm{~m}$, the error can be reached to $16.3 \%$. Therefore, it is needed to increase the calculated embedment depth of the defect when determining the location of the defect in the field test.

4.1.3. Effect of Length of Defect. Figure 8 shows the influence of the neck length on the velocity response of the pile top. It can be seen from Figure 8 that the neck length has marked influence on the velocity response. As the neck length increases from $0.5 \mathrm{~m}$ to $2.0 \mathrm{~m}$, the width and amplitude of RS1 and RS2 show marked increase. Moreover, the time of arrival of RS2 and RST is difficult to accurately identify with the increase of neck length.

Figure 9 shows the influence of the bulb length on the velocity response of the pile top. It can be seen from Figure 9 that the bulb length has marked influence on the velocity response of the pile top. When the bulb length increases from $0.5 \mathrm{~m}$ to $2.0 \mathrm{~m}$, the width and amplitude of RS1 and RS2 show marked increase, and the time of arrival of RS2 is difficult to obtain. However, the increase of bulb length has negligible influence on the amplitude and the time of arrival of RST.

Figure 10 shows the influence of the bulb length on the velocity response of the pile top. It can be seen from Figure 10 that the weak concrete length has marked influence on

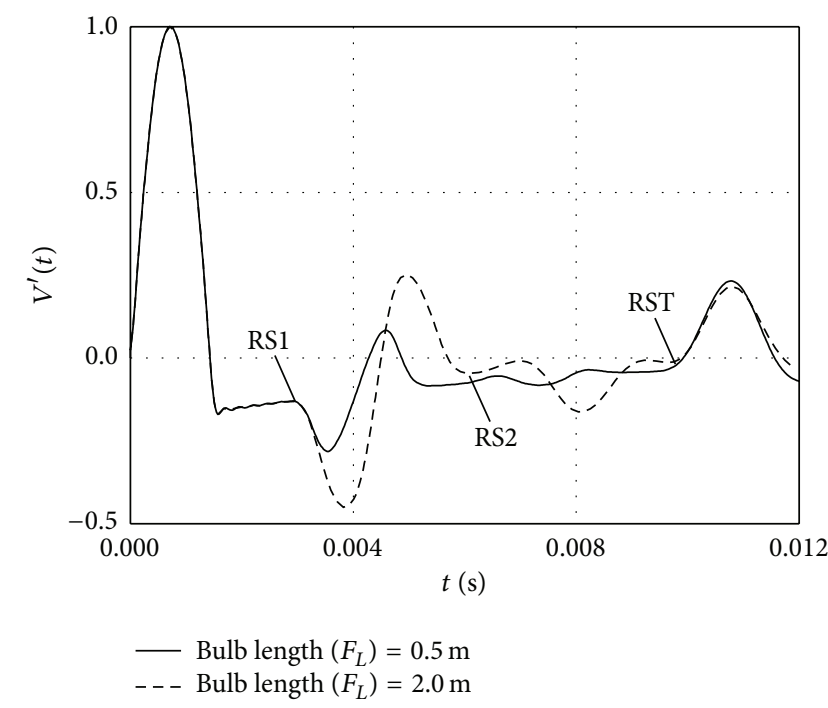

FIGURE 9: Variation of the normalized velocity response of the pile top with blub length $\left(N=3, W_{\mathrm{RB}}=0.70 \mathrm{~m}, F_{H}=h_{1}=6.0 \mathrm{~m}\right)$.

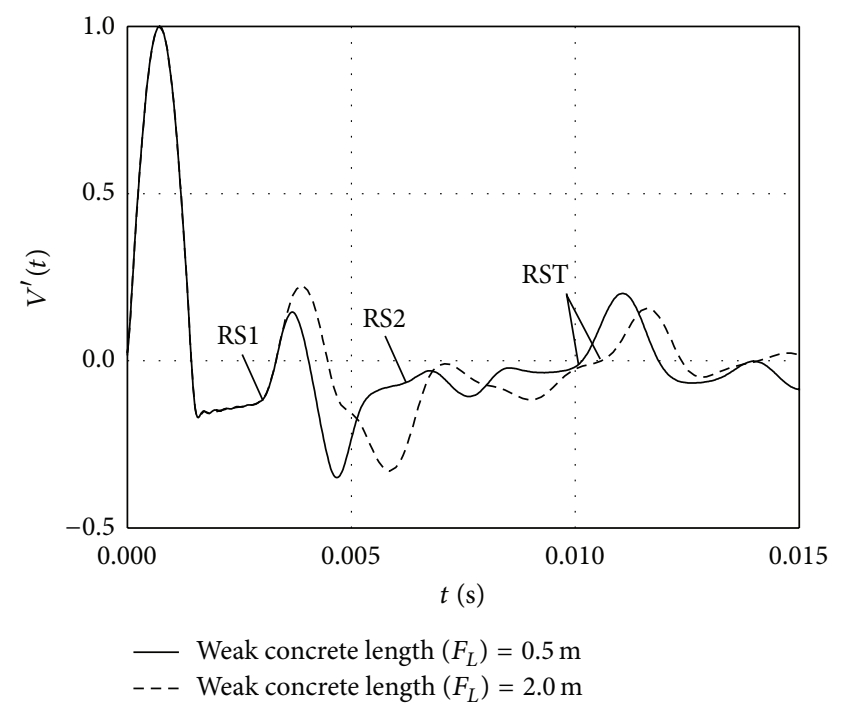

FIGURE 10: Variation of the normalized velocity response of the pile top with weak concrete length $\left(N=3, V_{P 2}=2000 \mathrm{~m} / \mathrm{s}, F_{H}=h_{1}=\right.$ $6.0 \mathrm{~m})$.

the velocity response of the pile top. As the weak concrete length increases from $0.5 \mathrm{~m}$ to $2.0 \mathrm{~m}$, the width and amplitude of RS1 and RS2 show marked increase. Furthermore, the time of arrival of RST increases with the increase of weak concrete length.

4.1.4. Effect of Surrounding Soil Properties. In some cases, the soil properties may change greatly in certain embedment depth. In order to explicitly identify the influence of the variation of the surrounding soil properties, the pile is assumed to be homogeneous and four cases of soil properties are investigated. Case 1: the shear velocity of soil layers decreases along the depth direction (namely, $V_{1}=60 \mathrm{~m} / \mathrm{s}$, 


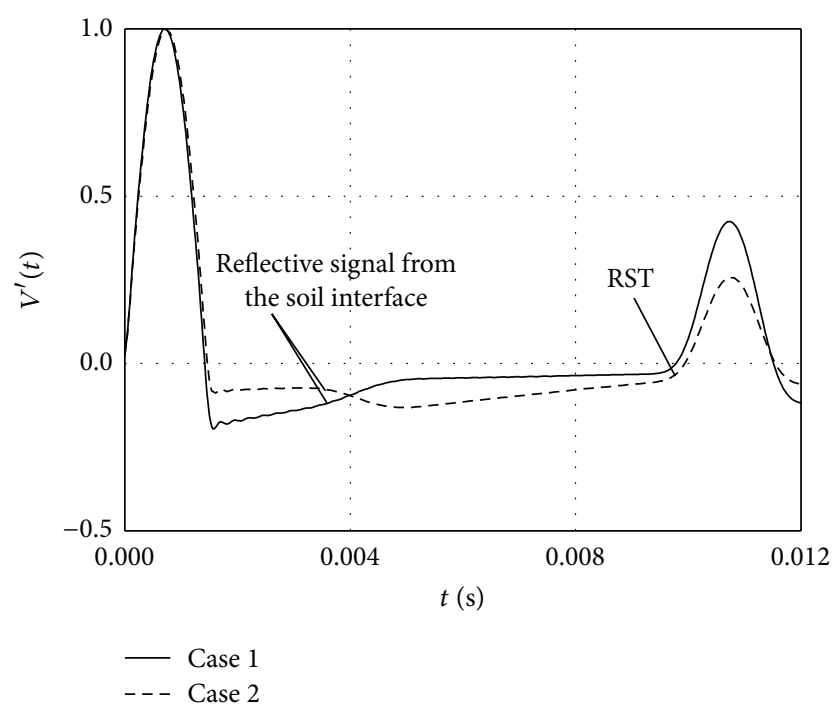

(a)

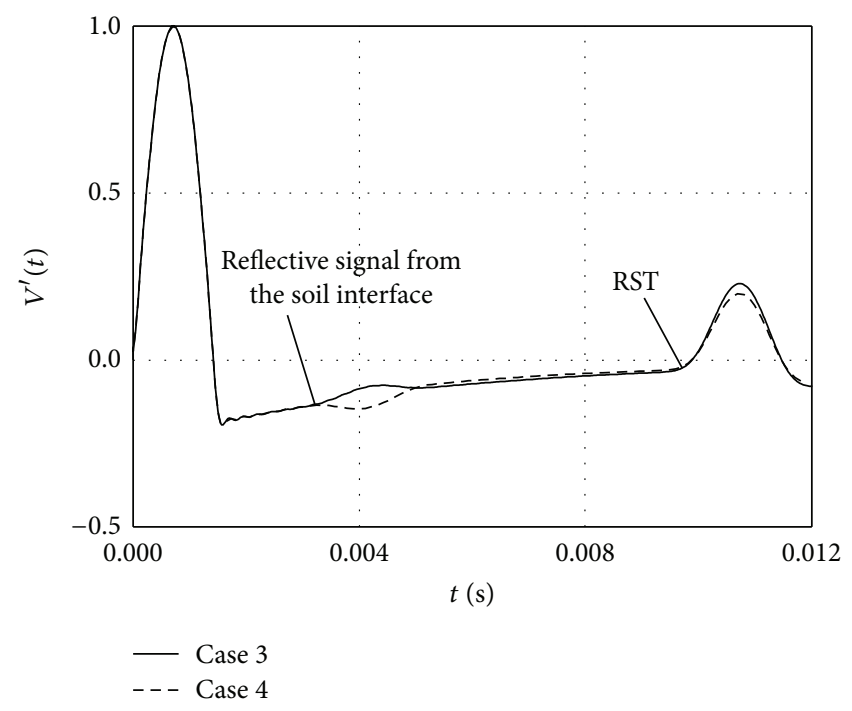

(b)

FIGURE 11: Effect of interface of adjacent soil layers on the normalized velocity response of the pile $\left(N=3, h_{1}=12.0 \mathrm{~m}, h_{2}=1.0 \mathrm{~m}\right.$, $\left.h_{3}=6.0 \mathrm{~m}\right)$.

$\left.V_{2}=100 \mathrm{~m} / \mathrm{s}, V_{3}=140 \mathrm{~m} / \mathrm{s}\right)$; Case $2:$ the shear velocity of soil layers increases along the depth direction (namely, $V_{1}=$ $\left.140 \mathrm{~m} / \mathrm{s}, V_{2}=100 \mathrm{~m} / \mathrm{s}, V_{3}=60 \mathrm{~m} / \mathrm{s}\right)$; Case 3: the soil has a soft interlayer (namely, $V_{1}=120 \mathrm{~m} / \mathrm{s}, V_{2}=60 \mathrm{~m} / \mathrm{s}, V_{3}=140 \mathrm{~m} / \mathrm{s}$ ); Case 4: the soil has a hard interlayer (namely, $V_{1}=120 \mathrm{~m} / \mathrm{s}$, $V_{2}=240 \mathrm{~m} / \mathrm{s}, V_{3}=140 \mathrm{~m} / \mathrm{s}$ ). It can be seen from Figure 11(a) that the velocity curve shows minor upward inclination, as the shear velocity of the soil gradually decreases along the depth direction. However, as the shear velocity of soil gradually increases along the depth direction, the velocity curve shows minor downward inclination. Based on these results, it can be concluded that the gradual variation of the surrounding soil properties along the depth has negligible influence on the identification of the defect in a pile. It can be seen from Figure 11(b) that the abrupt variation of the surrounding soil properties along the depth has certain influence on the velocity response of the pile. The phase of the reflective signal of the interface of adjacent soil layers is, respectively, the same as and opposite to that of the incident pulse for Case 3 and Case 4 . The shape of the reflective signal of the soil with a soft or hard interlayer is in a half-sine form, which is obviously different from that of the defective pile. Therefore, this result should be noted in the field test in case of identifying this kind of signal as a defect by mistake.

4.2. Pile Containing Multidefects. In Section 4.1, the mechanism of longitudinal wave propagating in a pile with a single defect has received detailed investigation. However, in practical engineering, a pile may contain more than one flaw along the pile body. It is noted that the reflected signals from different defects in the velocity curve may interact due to the existence of the potential second reflected signal from the defect. Therefore, the following section will take a pile with double defects as an example to illustrate the influence of the

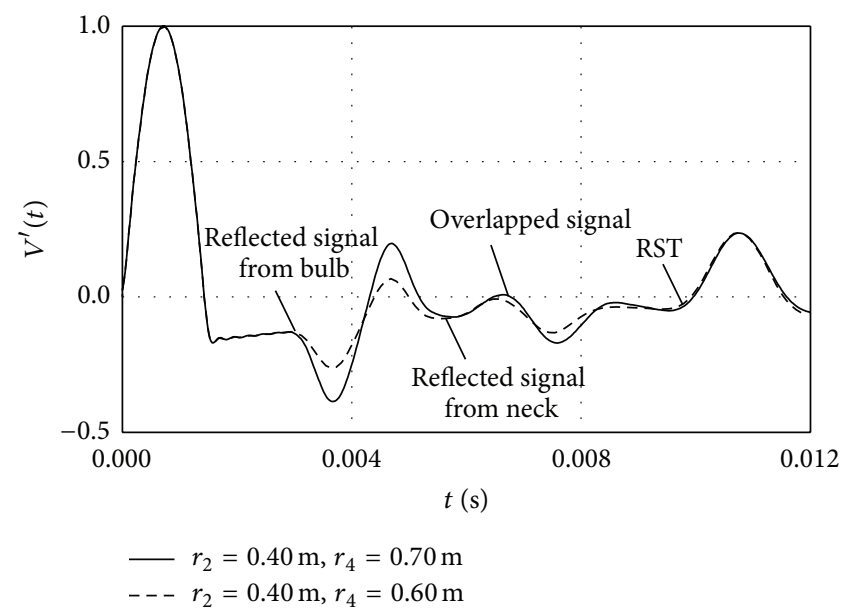

FIGURE 12: Time history of the normalized velocity response of the pile with bulb near the pile top and neck near the pile tip $(N=5$, $\left.h_{1}=7.0 \mathrm{~m}, h_{2}=0.5 \mathrm{~m}, h_{3}=4.5 \mathrm{~m}, h_{4}=1.0 \mathrm{~m}, h_{5}=6.0 \mathrm{~m}\right)$.

signal reflected from one defect near the pile top on the signal reflected from the other defect near the pile tip.

Figure 12 shows the time history of the velocity response of the pile with a bulb near the pile top and a neck near the pile tip. It can be seen from Figure 12 that the characteristics of the reflected signals from bulb and neck are obvious for $r_{4}=$ $0.60 \mathrm{~m}$ when considering the relative amplitude of the signals. However, the time of arrival of the reflected signal from the neck $(t \approx 0.00300 \mathrm{~s}$ ) is very close to that of the second reflected signal from the bulb $(t \approx 0.00591 \mathrm{~s})$ for $r_{4}=0.70 \mathrm{~m}$; accordingly the neck near the pile tip is easy to be identified as the second reflected signal from the bulb (referred to in Figure 9). The reason for this result is that the second reflected 


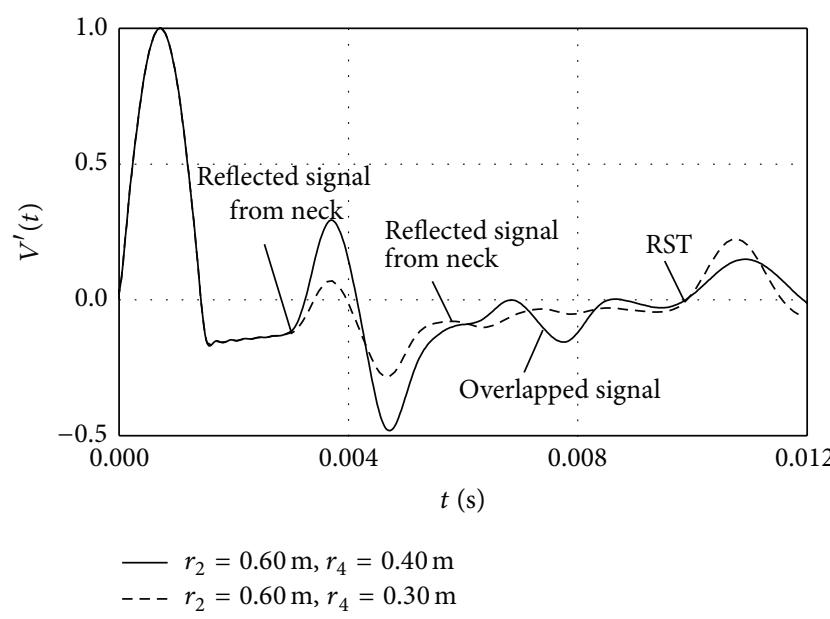

FIGURE 13: Time history of the normalized velocity response of the pile with neck near the pile top and bulb near the pile tip ( $N=5$, $\left.h_{1}=7.0 \mathrm{~m}, h_{2}=0.5 \mathrm{~m}, h_{3}=4.5 \mathrm{~m}, h_{4}=1.0 \mathrm{~m}, h_{5}=6.0 \mathrm{~m}\right)$.

signal from the bulb and reflected signal from the neck overlap in the time domain. Therefore, if the amplitude and width of the first reflected signal from the bulb are great, and the second reflected signal is obvious, other testing methods are suggested to further check the integrity of the pile.

Figure 13 shows the time history of the velocity response of the pile with a neck near the pile top and a bulb near the pile tip. It can be seen from Figure 13 that the characteristics of the reflected signals from the neck and bulb are obvious for $r_{4}=$ $0.40 \mathrm{~m}$. However, the reflected signal from the neck cannot be identified for $r_{4}=0.30 \mathrm{~m}$. The reason for this result is that the reflected signal from the bulb is overlapped and covered up by the second reflected signal from the neck. It is worth noting that this case will not influence the result of pile integrity test because of the existence of the neck near the pile top.

\section{Application in Engineering}

Figure 14 shows the comparison of the fitted theoretical curves and the measured curve from the model pile. The pile is an embedded, prefabricated, nonuniform square pile with a bulb near the pile top and a neck near the pile tip, which was installed at a site in China. The length and cross-sectional dimension of the pile are $10 \mathrm{~m}$ and $400 \mathrm{~mm} \times 400 \mathrm{~mm}$, respectively. Field measurements recorded the propagation time of the impulse traveling from the pile top to pile tip to pile top as $4.6 \mathrm{~ms}$. $1 \mathrm{D}$ elastic longitudinal wave velocity of the pile is estimated to be $4347.8 \mathrm{~m} / \mathrm{s}$. The surrounding soil is soft plastic viscoelastic backfill soil with mass density of $1700 \mathrm{~kg} / \mathrm{m}^{3}$ and shear wave velocity of $90 \mathrm{~m} / \mathrm{s}$. For the purpose of analysis, the square pile is considered as an equivalent circular pile with radius $r=225.5 \mathrm{~mm}$. The theoretical velocity curve has been derived through adjusting the radius, depths, and material damping of the pile segments as well as the duration of impulse to give a good fit to the measured curve. The fitted curves require the following

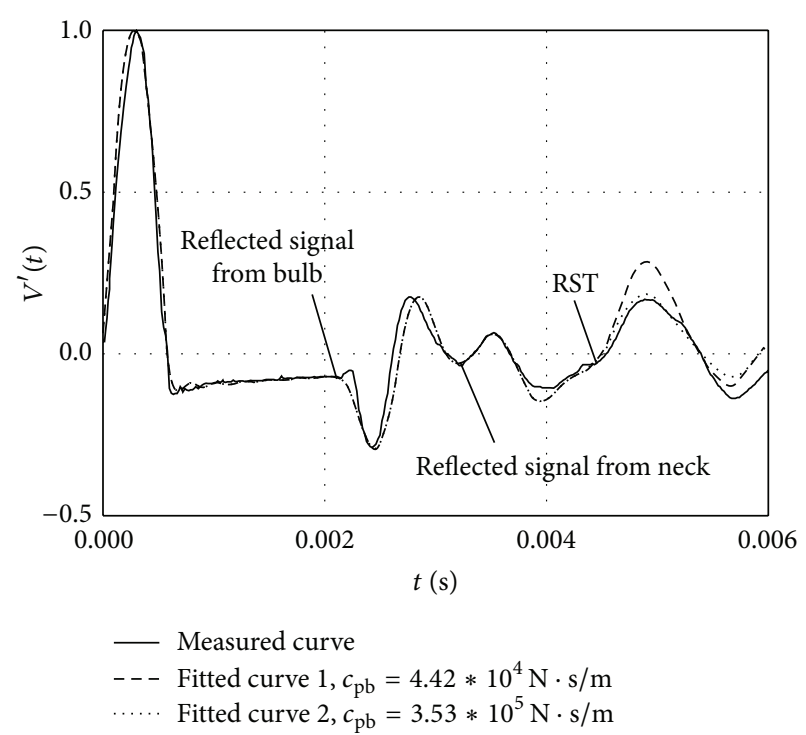

FIGURE 14: Comparison of the fitted theoretical curves and measured curve from the model pile.

input: (1) the embedment of the bulb is $4.9 \mathrm{~m}$, and the crosssectional area of the bulb to the normal shaft area is $210 \%$; (2) the embedment of the neck is $7.20 \mathrm{~m}$, and the crosssectional area of the neck decreased to a ratio of $54 \%$ of the normal shaft area; (3) the impulse width of the exciting force is $0.59 \mathrm{~ms}$, and the dimensionless damping coefficient of the pile $\bar{\eta}_{p j}=0.0015$. By comparison, the actual condition of the pile is listed as follows: at the depth of $4.8 \mathrm{~m}$, the enlarged area ratio is $200 \%$; at the depth of $7.16 \mathrm{~m}$, the crosssectional area decreased to a ratio of $55 \%$. Moreover, it is noted from Figure 14 that fitted curves 1 and 2 match well with the measured curve when $t<0.0045 \mathrm{~s}$. When $t>0.0045 \mathrm{~s}$, in the case of the damping coefficient at the pile toe $c_{\mathrm{pb}}$ taken in terms of (14), the amplitude of RST in fitted curve 1 is much higher than that in measured curve. However, RST in fitted curve 2 matches well with that in the measured curve, when $c_{\mathrm{pb}}$ is taken as a relatively great value. The reason for this result is that the amplitude of RST decreases with the increase of soil damping at the pile toe and the corresponding soil damping may be underestimated by virtue of (14) for the square pile.

\section{Conclusions}

(1) For a pile with a single neck, the phase of RS1 and RS2 is the same as that of the incident pulse. The amplitude of the signals reflected from the neck increases markedly with the decrease of the neck width.

(2) For a pile with a single bulb, the phase of RS1 is the opposite to that of the incident pulse. However, the phase of RS2 is the same as that of the incident pulse, which is easily identified as a defect by mistake. The amplitude of the signals reflected from the bulb increases greatly with the increase of bulb width. 
(3) For a pile with a single weak concrete, the phase of RS1 and RS2 is the same as that of the incident pulse due to the abrupt decrease of $V_{p 2}$ and the amplitude of RS1 increases greatly with the decrease of $V_{p 2}$. The time of arrival of RST increases obviously with the decrease of $V_{p 2}$.

(4) The amplitude and width of RS1 and RST, respectively, decrease and increase with the increase of pile material damping, which makes the degree of the defect seem to be smaller than the actual degree and the time of arrival of the signal reflected from the defect difficult to accurately identify.

(5) As the length of single defect (such as neck, bulb, or weak concrete) increases, the width and amplitude of RS1 and RS2 from the defect show marked increase. For a pile containing a neck, it is noted that the time of arrival of RST is difficult to identify with the increase of neck length.

(6) The gradual variation of the surrounding soil properties along the depth has negligible influence on identification of the defect in a pile. The abrupt change in adjacent soil layer properties has certain influence on the velocity response and this result should be noted in the field test in case of identifying this kind of signal as a defect by mistake.

(7) For a pile with a bulb near the pile top and a neck near the pile tip, when the amplitude and width of the first reflected signal from the bulb are great, and the second reflected signal is obvious, other testing methods are suggested to further check the pile integrity.

\section{Conflict of Interests}

The authors declare that there is no conflict of interests regarding the publication of this paper.

\section{Acknowledgments}

This research is supported by the National Natural Science Foundation of China (Grant no. 51378464), the National Science Foundation for Post-Doctoral Scientists of China (Grant no. 2013M541544), and the Shanghai Postdoctoral Sustentation Fund, China (Grant no. 13R21416200).

\section{References}

[1] M. Novak, T. Nogami, and F. Aboul-Ella, "Dynamic soil reaction for plane strain case," Journal of the Engineering Mechanical Division, vol. 104, no. 4, pp. 953-959, 1978.

[2] G. Militano and R. K. N. D. Rajapakse, "Dynamic response of a pile in a multi-layered soil to transient torsional and axial loading," Geotechnique, vol. 49, no. 1, pp. 91-109, 1999.

[3] K. H. Wang, D. Y. Yang, Z. Q. Zhang, and C. J. Leo, "A new approach for vertical impedance in radially inhomogeneous soil layer," International Journal for Numerical and Analytical Methods in Geomechanics, vol. 36, no. 6, pp. 697-707, 2012.

[4] S. H. Lü, K. H. Wang, W. B. Wu, and C. J. Leo, "Longitudinal vibration of a pile embedded in layered soil considering the transverse inertia effect of pile," Computers and Geotechnics, vol. 62, pp. 90-99, 2014.

[5] W. Wu, G. Jiang, S. Huang, and C. J. Leo, "Vertical dynamic response of pile embedded in layered transversely isotropic soil," Mathematical Problems in Engineering, vol. 2014, Article ID 126916, 12 pages, 2014.

[6] D. Y. Yang, K. H. Wang, Z. Q. Zhang, and C. J. Leo, "Vertical dynamic response of pile in a radially heterogeneous soil layer," International Journal for Numerical and Analytical Methods in Geomechanics, vol. 33, no. 8, pp. 1039-1054, 2009.

[7] W. M. Liu and M. Novak, "Dynamic response of single piles embedded in transversely isotropic layered media," Earthquake Engineering and Structural Dynamics, vol. 23, no. 11, pp. 12391257, 1994.

[8] A. G. Davis and C. S. Dunn, "From theory to field experience with the non-destructive vibration testing of piles," Proceedings of the Institution of Civil Engineers Part 2, vol. 57, no. 4, pp. 571593, 1974.

[9] A. G. Davis and S. A. Robertson, "Vibration testing of piles," Structural Engineer, vol. 54, no. 6, pp. A7-A10, 1976.

[10] J. S. Higgs, "Integrity testing of concrete piles by shock method," Concrete, vol. 13, no. 10, pp. 31-33, 1979.

[11] Y. Lin, M. Sansalone, and N. J. Carino, "Impact-echo response of concrete shafts," Geotechnical Testing Journal, vol. 14, no. 2, pp. 121-137, 1991.

[12] J. N. Watson, P. S. Addison, and A. Sibbald, "The de-noising of sonic echo test data through wavelet transform reconstruction," Shock and Vibration, vol. 6, no. 5-6, pp. 267-272, 1999.

[13] S. T. Liao and J. M. Roesset, "Dynamic response of intact piles to impulse loads," International Journal for Numerical and Analytical Methods in Geomechanics, vol. 21, no. 4, pp. 255-275, 1997.

[14] S. T. Liao and J. M. Roesset, "Identification of defects in piles through dynamic testing," International Journal for Numerical and Analytical Methods in Geomechanics, vol. 21, no. 4, pp. 277291, 1997.

[15] Y. K. Chow, K. K. Phoon, W. F. Chow, and K. Y. Wong, "Low strain integrity testing of piles: three-dimensional effects," Journal of Geotechnical and Geoenvironmental Engineering, vol. 129, no. 11, pp. 1057-1062, 2003.

[16] H. Y. Chai, K. K. Phoon, and D. J. Zhang, "Effects of the source on wave propagation in pile integrity testing," Journal of Geotechnical and Geoenvironmental Engineering, vol. 136, no. 9, pp. 1200-1208, 2010.

[17] Z. T. Lu, Z. L. Wang, and D. J. Liu, "Study on low-strain integrity testing of pipe-pile using the elastodynamic finite integration technique," International Journal for Numerical and Analytical Methods in Geomechanics, vol. 37, no. 5, pp. 536-550, 2013.

[18] S.-H. Ni, L. Lehmann, J.-J. Charng, and K.-F. Lo, "Low-strain integrity testing of drilled piles with high slenderness ratio," Computers and Geotechnics, vol. 33, no. 6-7, pp. 283-293, 2006.

[19] K. H. Wang, W. B. Wu, Z. Q. Zhang, and C. J. Leo, "Vertical dynamic response of an inhomogeneous viscoelastic pile," Computers and Geotechnics, vol. 37, no. 4, pp. 536-544, 2010. 
[20] T. Nogami and M. Novak, "Soil-pile interaction in vertical vibration," Earthquake Engineering and Structural Dynamics, vol. 4, no. 3, pp. 277-293, 1976.

[21] J. Lysmer and F. E. Richart, "Dynamic response of footing to vertical loading," Journal of the Soil Mechanics and Foundations Division, vol. 92, no. 1, pp. 65-91, 1966. 


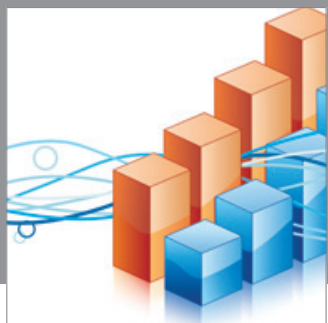

Advances in

Operations Research

mansans

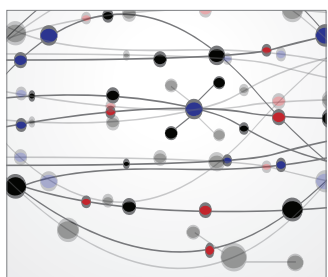

The Scientific World Journal
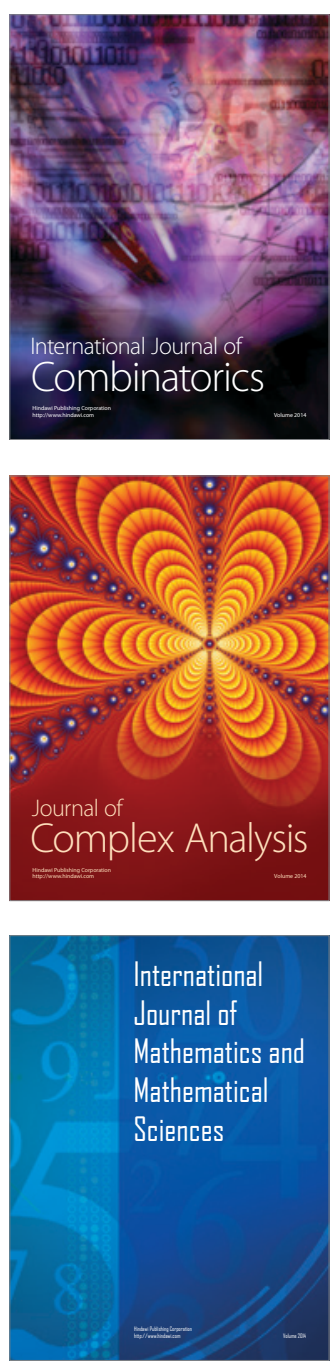
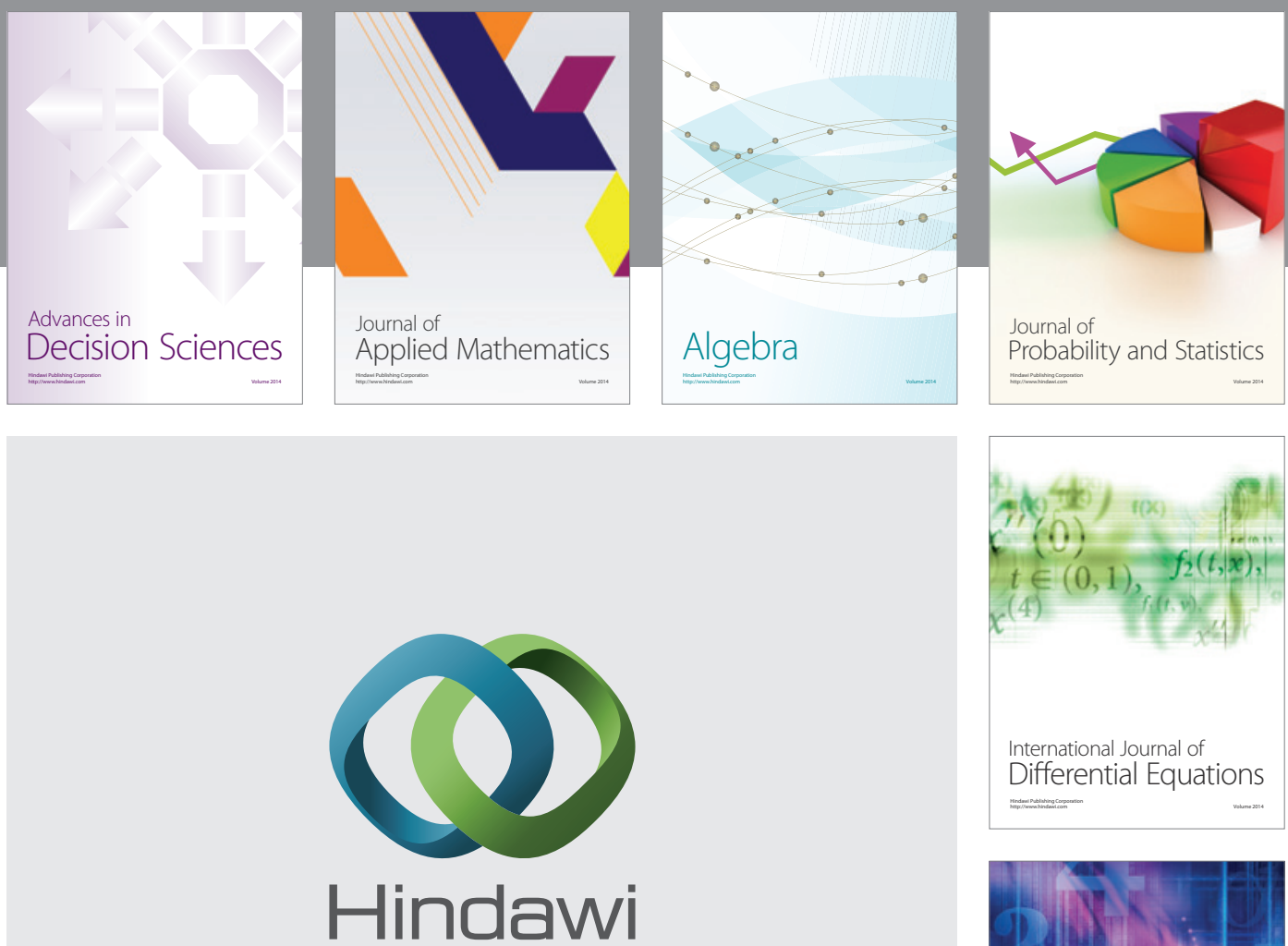

Submit your manuscripts at http://www.hindawi.com
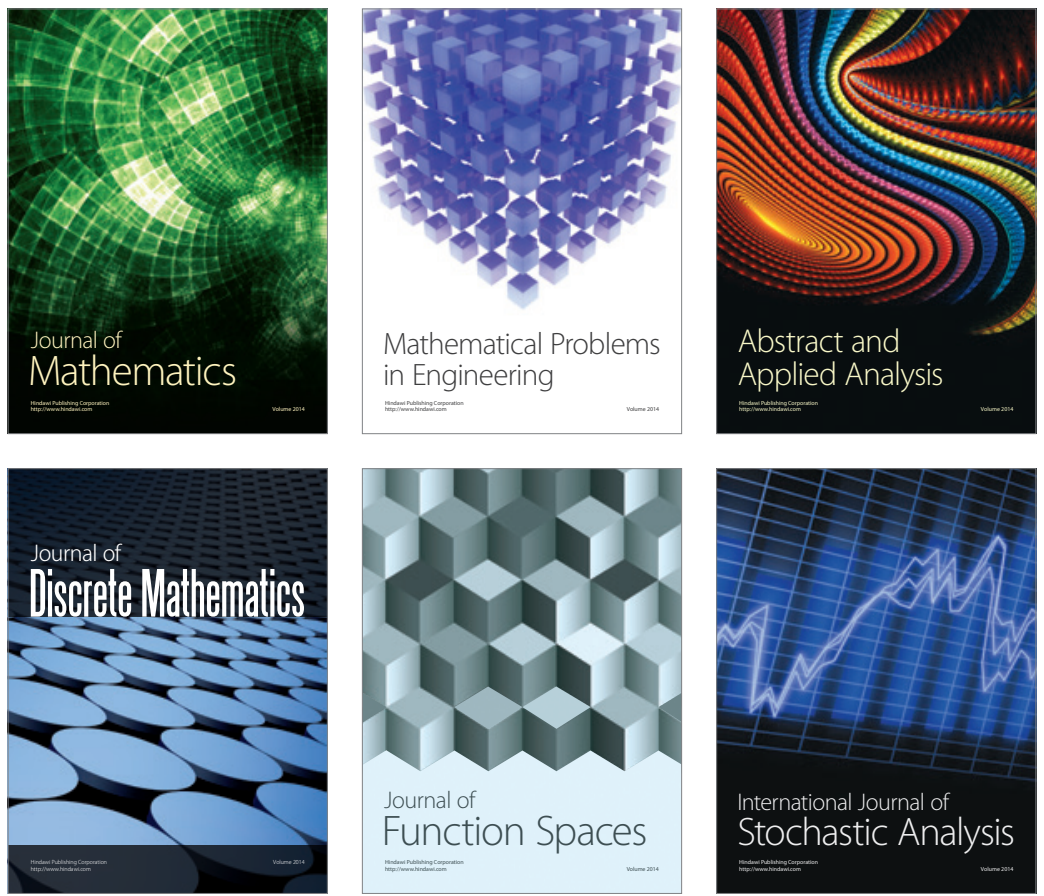

Journal of

Function Spaces

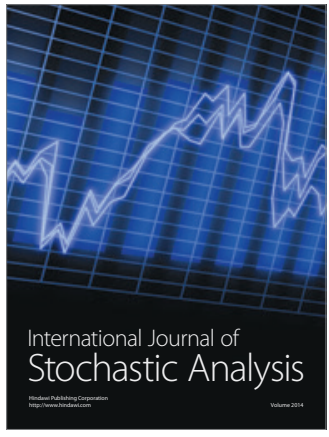

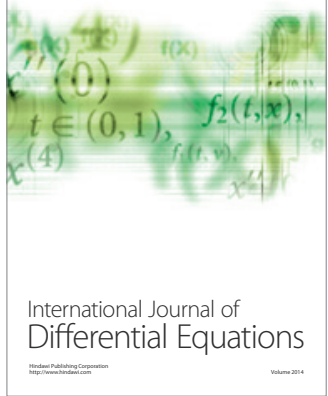
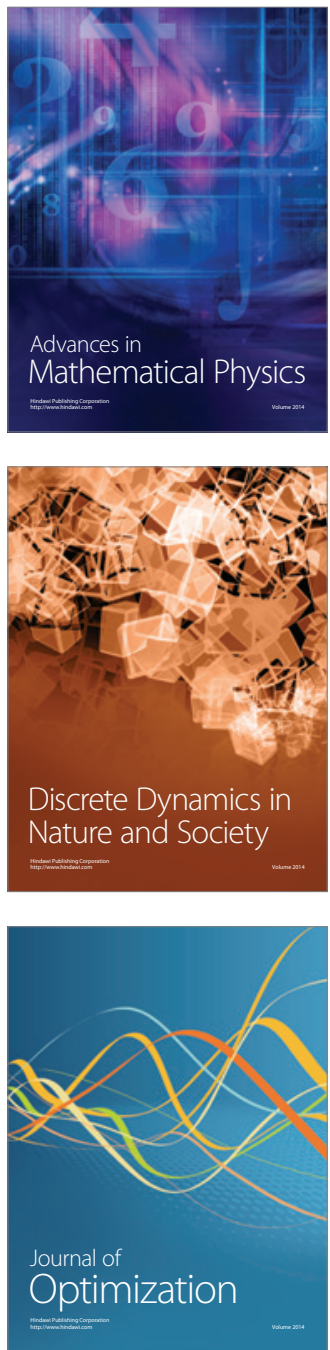